\title{
Determination of $\mathrm{Mn}, \mathrm{Fe}, \mathrm{Ni}$ in Copper Alloy by $\mathrm{X}$-Ray Fluorescence Analysis
}

\author{
Jie Shi, Yunrui Jiang, Bo Zhang, Jinge Zhou \\ School of Nuclear Technology \& Automation Engineering, Chengdu University of Technology, Chengdu, China \\ Email: az1278308130@163.com
}

How to cite this paper: Shi, J., Jiang, Y.R., Zhang, B. and Zhou, J.G. (2021) Determination of $\mathrm{Mn}, \mathrm{Fe}, \mathrm{Ni}$ in Copper Alloy by X-Ray Fluorescence Analysis. Open Access Library Journal, 8: e7844. https://doi.org/10.4236/oalib.1107844

Received: August 5, 2021

Accepted: August 24, 2021

Published: August 27, 2021

Copyright $\odot 2021$ by author(s) and Open Access Library Inc.

This work is licensed under the Creative Commons Attribution International License (CC BY 4.0).

http://creativecommons.org/licenses/by/4.0/

(c) (i) Open Access

\begin{abstract}
The basic principle of X-ray fluorescence analysis for the determination of impurity elements $\mathrm{Mn}, \mathrm{Fe}$ and $\mathrm{Ni}$ in copper alloy is introduced. On the basis of experiments, through theoretical analysis and experimental data, the variation trends of characteristic peak area and peak back ratio of $\mathrm{Mn}, \mathrm{Fe}$ and $\mathrm{Ni}$ elements with the change of light tube current and tube voltage are obtained, so as to establish the best working condition mode of different elements. The relative standard deviations of $\mathrm{Mn}, \mathrm{Fe}$ and $\mathrm{Ni}$ are $0.65 \%, 0.05 \%$ and $0.18 \%$ respectively. Multivariate regression analysis in the empirical coefficient method was used to establish a mathematical model to correct the matrix effect of $\mathrm{Mn}, \mathrm{Fe}$, and $\mathrm{Ni}$ elements. The experimental results show that the average absolute errors of $\mathrm{Mn}, \mathrm{Fe}$, and $\mathrm{Ni}$ content in copper alloys analyzed by the empirical coefficient method are $0.001 \%, 0.034 \%$, and $0.002 \%$, respectively, and the average relative errors are $0.698 \%, 2.205 \%$, and $0.110 \%$ respectively.
\end{abstract}

\section{Subject Areas}

Application of Nuclear Technology

\section{Keywords}

X-Ray Fluorescence Analysis, Copper Alloy, Accuracy, Matrix Effect

\section{Introduction}

Copper is the earliest metal recognized and used by mankind, and its output occupies the second place among non-ferrous metals. Electrical and thermal conductivity is the most important application area of copper and its alloys. The presence of impurity elements will increase its hardness and decrease its electrical conductivity. Copper alloys are generally used as structural materials. In addition, copper alloys are often seen in functional materials. The physical and me- 
chanical properties of copper alloys are closely related to their chemical composition [1]. Therefore, the chemical composition of copper alloys needs to be quickly analyzed during the production and processing of copper alloys. X-ray fluorescence spectroscopy is a fast and non-destructive analysis method with fast analysis speed, high automation, good reproducibility and wide measurement range [1] [2] [3]. The content of manganese, iron, nickel and other impurity elements in copper alloy was determined by energy dispersive X-ray fluorescence analyzer (EDXRF), and good results were obtained.

\section{Basic Principles}

According to Moseley's law, the square of the atomic number is proportional to the energy of the characteristic ray. If the atomic number is different, the characteristic ray generated after being excited will be different. The purpose of the $\mathrm{X}$-ray fluorescence quantitative analysis method is to calculate the content of the element to be measured in the sample through the count rate obtained by the measurement. Therefore, one can first determine the material composition of the sample, calculate the proportional coefficient, and then calculate the content of the element to be measured according to the counting rate.

$$
W_{K}=\frac{\mu_{0}+\mu_{K}}{K I_{0}} \cdot I_{K}
$$

In the formula, $W_{K}$ is the content of the element to be measured, and $I_{K}$ is the counting rate measured by the element to be measured; $\left(\mu_{0}+\mu_{K} / K I_{0}\right)$ is the scale factor.

\section{Experimental Instrument and Working Conditions}

\subsection{Experimental Equipment and Sample Preparation}

The experimental samples are selected from the GSB04-2415-2008T00-09 series of copper alloy standard samples. The solid samples are cylindrical and the size is: $\Phi 40 \mathrm{~mm} \times 20 \mathrm{~mm}$ (height). Since the surface finish of the metal sample directly affects the X-ray fluorescence intensity, this effect is related to the element to be measured, so when measuring, the end of the sample without characters is polished with a lathe and then wiped clean with medical cotton.

The instrument selected in this experiment is PANalytical Desktop XRF Spectrometer Epsilon 1: Ag anode X-ray tube and high current (3 mA) SDD detector, the maximum voltage of the $\mathrm{X}$-ray tube is $50 \mathrm{kV}$, and the maximum current is $500 \mu \mathrm{A}$. The maximum power is $5 \mathrm{~W}$. The measuring element range is $\mathrm{Na}-\mathrm{Am}$, the resolution $(\mathrm{Mg}-\mathrm{K \alpha}): 135 \mathrm{eV}$, and the detection limit is $1 \mathrm{ppm}-100 \%$.

\subsection{Experimental Condition Setting}

In order to obtain higher measurement precision and lower detection limit, the highest possible count rate and good peak-to-background ratio should be obtained in the measurement process; especially the measurement time of trace elements should be appropriately increased to improve the analysis accuracy. On 
the basis of experiments, the variation laws of characteristic peak area and peak to back ratio of $\mathrm{Mn}, \mathrm{Fe}$ and $\mathrm{Ni}$ with photocell current and tube voltage are obtained through theoretical analysis and experimental data, so as to obtain the best working mode of measurement, as shown in Table 1.

\section{Matrix Effect Correction}

In fact, the elements that have a significant contribution to the matrix effect are those elements that have high content, large content changes, and strong absorption or enhancement of the characteristic fluorescence to be measured. Therefore, by processing such major interference elements separately, a more accurate matrix effect correction effect will be obtained. At this time, the mathematical correction method can be used, which is characterized by quantifying the interaction between the elements in the matrix and expressing it in various mathematical models, so that various calculation methods can be used to complete the correction of the matrix effect, mainly the correction of the effect between the elements. Matrix effect correction adopts multivariate statistical analysis of empirical coefficient method, and the established mathematical model is as follows:

$$
W_{i}=a_{i 0}+a_{i} I_{i}+\sum_{j=0, j \neq i}^{N} a_{i j} I_{j}
$$

In the formula, $W_{i}$ is the content of the target element, $I_{i}$ and $I_{j}$ are the intensity of the target element and the interference element respectively; $a_{i 0}, a_{i}$ and $a_{i j}$ are the empirical coefficients, which can be obtained through multiple linear regression analysis.

\section{Results and Discussion}

\subsection{Calculation of Accuracy}

Accuracy refers to the consistency between repeated analysis results when analyzing the same sample. The more consistent the results of repeated analysis are, the higher the accuracy is. The accuracy of the analysis depends on the size of the accidental error in the measurement process. The evaluation of the accuracy is obtained through statistics of the relative standard deviation obtained from the same sample. The formula is as follows:

$$
R S D=\frac{\sqrt{\frac{\sum_{i=1}^{n}\left(I_{i}-I_{A V E}\right)^{2}}{n-1}}}{I_{A V E}} \times 100 \%
$$

Table 1. Optimum analysis conditions of EDXRF.

\begin{tabular}{ccccccc}
\hline Element & Spectral line & Tube voltage $(\mathrm{kV})$ & Tube current $(\mu \mathrm{A})$ & Filter & Condition set & Time $(\mathrm{s})$ \\
\hline $\mathrm{Mn}$ & $\mathrm{Ka}$ & 20 & 27 & Al-200 & Cr-Co & 600 \\
$\mathrm{Fe}$ & $\mathrm{Ka}$ & 20 & 27 & Al-200 & Cr-Co & 600 \\
$\mathrm{Ni}$ & $\mathrm{Ka}$ & 27 & 23 & Al-200 & Ni-Mo & 600 \\
\hline
\end{tabular}


In the formula, $I_{i}$ is the count rate, $I_{A V E}$ is the average count rate; $R S D$ is the relative standard deviation. Take the ZC-4 copper alloy standard sample as the inspection object, and measure 10 times continuously under the same conditions. The test results are shown in Table 2. It can be seen in the table that the relative standard deviations of $\mathrm{Mn}, \mathrm{Fe}$, and $\mathrm{Ni}$ are $0.65 \%, 0.05 \%$, and $0.18 \%$, respectively, which shows that the accuracy of the analysis is high.

\subsection{Analytic Result}

The empirical coefficient method was used to analyze the content of $\mathrm{Mn}, \mathrm{Fe}$, and $\mathrm{Ni}$ elements in the copper alloy samples, and the analysis results are shown in Table 3. Perform ternary linear regression analysis for Mn element, and get the correlation $\mathrm{r}^{2}=0.999$, the average absolute error of $\mathrm{Mn}$ content analysis result is $0.001 \%$, and the average relative error is $0.698 \%$; for Fe element, perform ternary linear regression analysis to get its correlation $r^{2}=0.998$, the average absolute error of the $\mathrm{Fe}$ content analysis result is $0.034 \%$, the average relative error is 2.205\%; the quaternary linear regression analysis for Ni element, the correlation $r^{2}=0.999$, the average absolute error of the $\mathrm{Ni}$ content analysis result It is $0.002 \%$, and the average relative error is $0.110 \%$. Therefore, calibration models for analyzing $\mathrm{Mn}, \mathrm{Fe}$, and $\mathrm{Ni}$ in copper alloy samples can be established respectively [4] [5].

Table 2. Method accuracy results.

\begin{tabular}{cccc}
\hline Element & Mn & Fe & Ni \\
\hline Average count rate (cps) & 151.12 & 3657.49 & 598.06 \\
Standard deviation & 0.98 & 1.89 & 1.11 \\
RSD (\%) & 0.65 & 0.05 & 0.18 \\
\hline
\end{tabular}

Table 3. Analysis and comparison results of copper alloy samples.

\begin{tabular}{|c|c|c|c|c|c|c|c|c|c|c|c|c|}
\hline \multirow{2}{*}{$\begin{array}{c}\text { Serial - } \\
\text { number }\end{array}$} & \multicolumn{4}{|c|}{ Mn (\%) } & \multicolumn{4}{|c|}{$\mathrm{Fe}(\%)$} & \multicolumn{4}{|c|}{$\mathrm{Ni}(\%)$} \\
\hline & $\begin{array}{l}\text { actual } \\
\text { value }\end{array}$ & $\begin{array}{c}\text { calculated } \\
\text { value }\end{array}$ & $\begin{array}{l}\text { absolute } \\
\text { error }\end{array}$ & $\begin{array}{c}\text { fractional } \\
\text { error }\end{array}$ & $\begin{array}{l}\text { actual } \\
\text { value }\end{array}$ & $\begin{array}{l}\text { calculated } \\
\text { value }\end{array}$ & $\begin{array}{l}\text { absolute } \\
\text { error }\end{array}$ & $\begin{array}{c}\text { fractional } \\
\text { error }\end{array}$ & actual value & $\begin{array}{l}\text { calculated } \\
\text { value }\end{array}$ & $\begin{array}{l}\text { absolute } \\
\text { error }\end{array}$ & $\begin{array}{c}\text { fractional } \\
\text { error }\end{array}$ \\
\hline 1 & 0.001 & 0.001 & 0.000 & -0.378 & 0.076 & 0.077 & 0.001 & 1.160 & 0.081 & 0.079 & -0.002 & -2.457 \\
\hline 2 & 0.001 & 0.001 & 0.000 & -4.071 & 0.039 & 0.041 & 0.002 & 5.576 & 0.075 & 0.077 & 0.002 & 2.577 \\
\hline 3 & 0.188 & 0.191 & 0.003 & 1.434 & 3.702 & 3.756 & 0.054 & 1.470 & 0.425 & 0.426 & 0.001 & 0.209 \\
\hline 4 & 0.021 & 0.021 & 0.000 & -1.013 & 0.534 & 0.542 & 0.008 & 1.430 & 0.420 & 0.423 & 0.003 & 0.783 \\
\hline 5 & 0.016 & 0.018 & 0.002 & 9.408 & 0.520 & 0.530 & 0.010 & 1.862 & 0.465 & 0.466 & 0.001 & 0.191 \\
\hline 6 & 0.189 & 0.189 & 0.000 & 0.137 & 3.791 & 3.867 & 0.076 & 2.005 & 0.425 & 0.428 & 0.003 & 0.788 \\
\hline 7 & 0.195 & 0.192 & 0.003 & -1.497 & 3.810 & 3.675 & -0.135 & -3.550 & 0.423 & 0.419 & -0.004 & -1.007 \\
\hline 8 & 0.651 & 0.651 & 0.000 & -0.001 & 0.501 & 0.501 & 0.000 & -0.004 & 16.042 & 16.042 & 0.000 & 0.000 \\
\hline 9 & 0.017 & 0.016 & 0.001 & -7.517 & 0.703 & 0.687 & -0.016 & -2.206 & 0.421 & 0.417 & -0.004 & -0.972 \\
\hline AVE & 0.142 & 0.142 & 0.001 & 0.698 & 1.520 & 1.520 & 0.034 & 2.205 & 2.086 & 2.086 & 0.002 & 0.110 \\
\hline
\end{tabular}




$$
\begin{gathered}
W_{\mathrm{Mn}}=0.0045+0.0013 I_{\mathrm{Mn}}-5.34 \times 10^{-8} I_{\mathrm{Ni}}-4.15 \times 10^{-8} I_{\mathrm{Cu}} \\
W_{\mathrm{Fe}}=0.1233+0.0011 I_{\mathrm{Fe}}-1.74 \times 10^{-6} I_{\mathrm{Ni}}-1.70 \times 10^{-6} I_{\mathrm{Cu}} \\
W_{\mathrm{Ni}}=0.0387+0.00061 I_{\mathrm{Ni}}-2.26 \times 10^{-5} I_{\mathrm{Fe}}-0.0004 I_{\mathrm{Mn}}-0.0018 I_{\mathrm{Cu}}
\end{gathered}
$$

In the formula, $W_{\mathrm{Mn}}, W_{\mathrm{Fe}}$, and $W_{\mathrm{Ni}}$ are the content of the target element, $I_{\mathrm{Mn}}$, $I_{\mathrm{Fe}}, I_{\mathrm{Ni}}$, and $I_{\mathrm{Cu}}$ are the count rate.

\section{Conclusion}

In summary, it is feasible to use X-ray fluorescence analysis to analyze the content of impurity elements in copper alloys. For the XRF analysis of the content of impurity elements in copper alloys, the empirical coefficient method can be used to correct the matrix effect, and the correction effect is better. The X-ray fluorescence analysis method can quickly detect the element content in the copper alloy. The detection speed is fast, efficient, convenient, and has good economic benefits.

\section{Acknowledgements}

Thanks to Yunrui Jiang, Bo Zhang and Jinge Zhou' great help in experimental design, I can write smoothly.

\section{Conflicts of Interest}

The authors declare no conflicts of interest.

\section{References}

[1] Paltridge, N.G., Palmer, L.J., Milham, P.J., et al. (2012) Energy-Dispersive X-Ray Fluorescence Analysis of Zinc and Iron Concentration in Rice and Pearl Millet Grain. Plant Soil, 361, 251-260. https://doi.org/10.1007/s11104-011-1104-4

[2] Lugendo, I., Mohammed, N.K., Mussa, L.M., et al. (2013) Assessment of the Lake Gendabi Salt for Trace Elements and Toxic Heavy Metals by Energy Dispersive X-Ray Fluorescence Spectrometry. Journal of Radioanalytical and Nuclear Chemistry, 297, 215-220. https://doi.org/10.1007/s10967-012-2367-9

[3] Ali, M., Choudhury, T.R., Hossain, B., et al. (2014) Determination of Traces of Molybdenum and Lead in Foods by X-Ray Fluorescence Spectrometry. Springer Plus, 3, Article No. 341. https://doi.org/10.1186/2193-1801-3-341

[4] Calzolai, G., et al. (2008) PIXE and XRF Analysis of Particulate Matter Samples: An Inter-Laboratory Comparison. Nuclear Instruments and Methods in Physics Research B: Beam Interactions with Materials and Atoms, 266, 2401-2404. https://doi.org/10.1016/j.nimb.2008.03.056

[5] Kilbride, C., Poole, J. and Hutchings, R. (2006) A Comparison of Cu, Pb, As, Cd, $\mathrm{Zn}, \mathrm{Fe}, \mathrm{Ni}$ and $\mathrm{Mn}$ determined by Acid Extraction/ICP-OES and ex Situ Field Portable X-Ray Fluorescence Analyses. Environmental Pollution, 143, 16-23. https://doi.org/10.1016/j.envpol.2005.11.013 